\title{
MORPHOFUNCTIONAL ACTIVITY OF NUCLEOLAR ORGANIZERS OF RAT NEPHROCYTES UNDER PHARMACOLOGICAL CORRECTION OF EXPERIMENTAL OXALATE NEPHROLITHIASIS BY PEPTIDE COMPLEX OF PIG KIDNEY TISSUE
}

\author{
Altai State Medical University, Barnaul \\ G.V. Zharikova, I.P. Bobrov, O.N. Mazko, O.G. Makarova, A.V. Lepilov, A.Yu. Zharikov
}

\begin{abstract}
The aim of the present research is to study the influence of the peptide complex of pig kidneys tissue on the morphofunctional activity of nucleolar organizers of nephrocytes under experimental oxalate nephrolithiasis. Experiments were conducted on 24 male Wistar rats which were divided into 2 groups: a control group (6 weeks of oxalate nephrolithiasis modeling) and a test group (6 weeks of oxalate nephrolithiasis modeling + injecting the peptide complex at a dose of $15 \mathrm{mg}$ ). Detecting of nucleolar organizers was carried out with a modified $Y$. Daskal's method.

Studies revealed that with the use of the peptide complex of pig kidneys tissue an enchancement of biosynthetic processes in nephrocytes could be noticed, as an increase in morphofunctional activity of nucleolar organizers of kidney cells could be observed in comparison with a control group. An increase in activity of nucleolar cell apparatus appeared both in their increase of number of nucleoli and number of silver granules (core structures) and the increase of cell count with a large number of core structures for 1 nucleus.
\end{abstract}

Key words: peptide complex of pig kidneys tissue, nephrolithiasis, nucleolar organizers.

The development of new effective and safe medicines for the treatment of urolithiasis is a crucial task of modern pharmacology and urology.

Nowadays, there are experimentally justified prerequisites for the creation of a new antilithogenic agent of peptide nature. Earlier we obtained an experimental peptide complex from lyophilisate of pig kidney tissue, identified its amino acid composition and tested the curative effect on the experimental model of oxalate nephrolithiasis. It turned out that a three-week oral administration of the obtained peptide complex at a dose of $15 \mathrm{mg}$ was accompanied by the destruction of large and medium uroliths to fine dust granularity [1,2].

As is known, in the kidneys, so-called crystallization inhibitors form and function: these are high-molecular proteins preventing stone formation [3]. It is possible that the introduced peptides having a nuclear orientation of action could stimulate the formation of cellular proteins, including crystallization inhibitors. In this regard, we decided to study the impact of the peptide complex of pig kidney tissue on biosynthetic processes in nephrocytes under experimental oxalate nephrolithiasis. Thus, the aim of the present research is to study the influence of the peptide complex of pig kidneys tissue on the morphofunctional activity of nucleolar organizers of nephrocytes under experimental oxalate nephrolithiasis.

\section{Materials and methods}

The study was conducted on 24 male Wistar rats weighing 200-250 g, being on a standard laboratory diet, receiving $30-40 \mathrm{~g}$ of daily food for laboratory rodents produced by ZAO Assortiment-Agro under the Chara trade mark. Animals were divided equally into two groups: the control one and the test one. Experimental oxalate nephrolithiasis was modeled in the control group without the introduction of pharmacologically active substances [4]. According to the nephrolithiasis model used, rats received the $1 \%$ ethylene glycol aqueous solution daily in the form of the drink at free access. In the same conditions of nephrolithiasis modeling, rats of the test group received the peptide complex obtained by the method of the acetic extraction from lyophilisate of pig kidney tissue in the form of the starch suspension orally through a probe at a dose of $15 \mathrm{mg}$ from day 22 to day 42 of the experiment.

Chromatographic analysis of the peptide complex of pig kidney tissue through the method of high-performance liquid chromatography (HPLC) on the Milichrom-A02 chromatograph without hydrolysis showed that its composition consists of about 30 chromatographically significant peaks in the range of the retention volume from 0 to 2500 $\mu \mathrm{l}$. The capillary electrophoresis method on the CAPEL $®-105 \mathrm{M}$ capillary electrophoresis system with positive high voltage polarity in hydrochloric hydrolysate of the obtained peptide complex of pig kidney tissue allowed to identify 14 amino acids: arginine, lysine, tyrosine, phenylalanine, histidine, leucine, isoleucine, methionine, valine, proline, threonine, serine, alanine, glycine with a total mass fraction of $49.778 \%$.

After six weeks of the experiment, rats of both groups were subjected to decapitation under ether anesthesia in compliance with the requirements of 
the Declaration of Helsinki of the World Medical Association (2000). The rat kidney was the material of the study. The organ was fixed in the $10 \%$ formalin solution, processed according to the standard method, poured into paraffin.

For histological examination, kidney tissue was fixed in the $10 \%$ neutral formalin solution, processed according to the standard method and poured into paraffin. 4-5 $\mu \mathrm{m}$ thick histological sections were coloured with haematoxylin and eosin and with a histochemical method in order to reveal nucleolar organizers. Nucleolar organizers were revealed according to the two-stage method of Daskal Y. et al. [5] in our modification [6, 7]. With an increase $x 1000$ under the oil immersion of the microscope, the number of nucleoli and the number of silver granules in nucleoli per 1 nucleus were calculated, histograms of cell distribution by the number of granules per 1 nucleus were constructed. In each case, at least 50 nephrothelium cells were studied.

Statistical processing of the material was carried out with the use of the Statistica 10.0 statistical

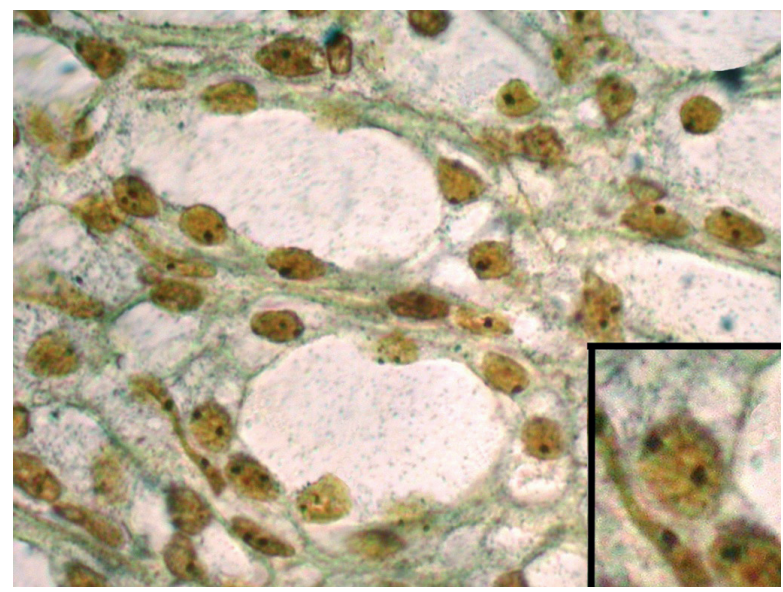

$1 \mathrm{a}$ package. In the normal distribution of data, the methods of parametric statistics (Student t-test) were used while checking statistical hypotheses, and if the obtained data did not meet the criteria of normal distribution (Shapiro-Wilk test $\mathrm{W}=0.89$, $\mathrm{p}<0.01)$, the Kolmogorov-Smirnov test or MannWhitney U-test was applied. The data was considered reliable at $\mathrm{p}<0.05$.

\section{Results and discussion}

The conducted experiments on the assessment of the morphofunctional activity of nucleolar organizers of cells of the renal papilla collecting tubules revealed that in the control group, the number of silver granules in nucleoli per 1 nucleus amounted to $2.5 \pm 0.1$, margins of fluctuations of the number of granules varied from 1 to 3 granules, the modal value was 3 granules. The number of nucleoli in cell nucleuses averaged 2.0 \pm 0.1 , margins of fluctuations of the number of nucleoli ranged from 1 to 3 nucleoli, the modal value was 2 nucleoli (Figure 1a).

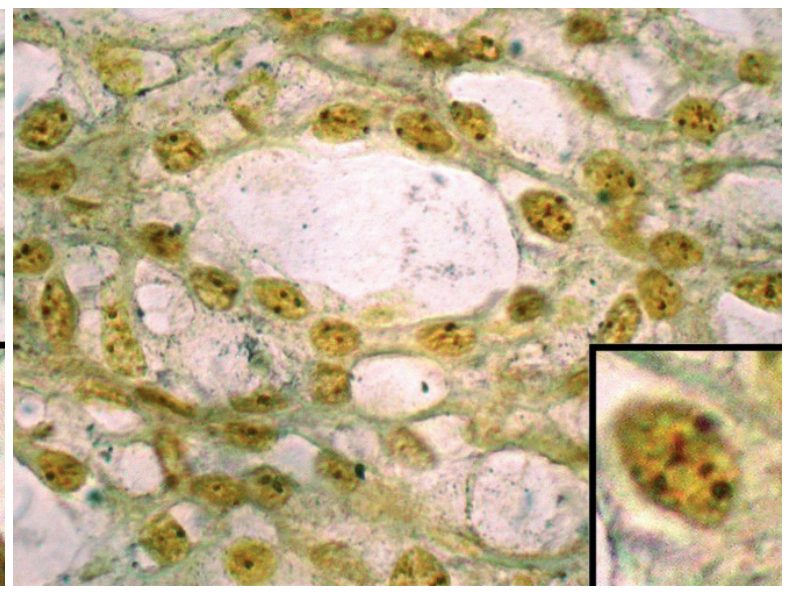

$1 b$

Figure 1. Microphotograph of nucleolar organizers in nephrocytes (the enlarged fragment of the microphotograph is within the frame). Colouring with silver nitrate by Y. Daskal in the modification of I.P. Bobrov. Enlargement x1000. 1a - a small amount in the study control group.

$1 \mathrm{~b}$ - a large number of nucleolar organizers in the study test group.

The distribution of cell elements depending on the number of silver granules per 1 nucleus revealed that the histogram of distribution has a left shift and is characterized by high peaks in the cell areas having 2 and 3 granules per 1 nucleus (Figure 2).

Against this background, in the kidneys of rats of the test group, where the peptide complex of pig kidney tissue was introduced for 3 weeks, the evidence of a significant increase in biosynthetic processes was obtained.

It turned out that the test group compared to the disease control showed a significant increase $(p=0.0000001)$ to $3.4 \pm 0.1$ in the average number of silver granules in nucleoli per 1 nucleus, margins of fluctuations ranged from 2 to 7 granules, the modal value made 3 granules. The number of nucleoli in this group was also reliably larger on the average $(p=0.000035)$ than in the control group, margins of fluctuations of the number of nucleoli ranged from 1 to 4 nucleoli, the model value was 3 nucleoli (Figure 1b).

The distribution of cell elements depending on the number of silver granules per 1 nucleus in this group revealed that the histogram of distribution has a right shift and is characterized by high peaks in the cell areas having 3 and 4 granules per 1 nucleus. With that, in comparison to the control group, there were cells with 7 granules $(2 \%)$ per 1 nucleus. There were no cells with 1 granule per 1 nucleus, and the cell content with 2 granules was reduced (Figure 2). 


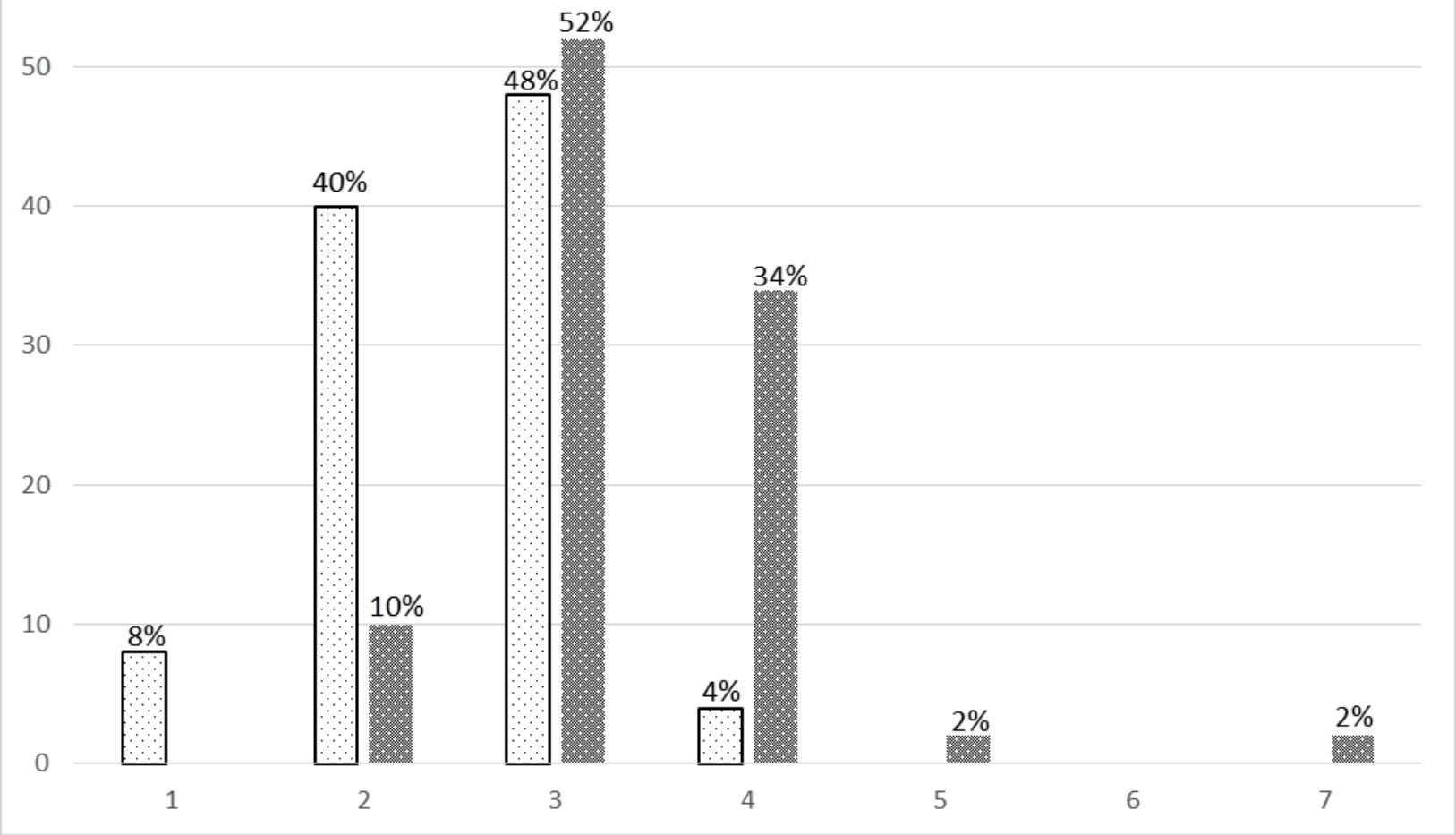

Figure 2. Histogram characterizing cell distribution by the number of silver granules in kidney cells. Note: along the x-axis - the number of silver granules, along the y-axis - the percentage of cells.

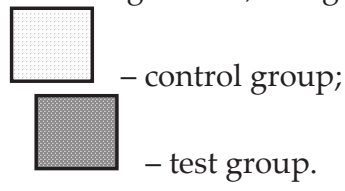

Thus, the results of the study conducted showed that in the application of the peptide complex of pig kidney tissue, there was an increase in morphofunctional activity of nucleolar organizers of kidney cells in comparison to the control group. An increase in activity of nucleolar cell apparatus appeared both in their increase of number of nucleoli and number of silver granules (core structures) and the increase of cell count with a large number of core structures for 1 nucleus.

As is known, the nucleolus is a dynamic structure, its morphology is closely connected to the ribosome biogenesis: preribosomal RNA synthesis, processing and migration of RNP particles into nucleoplasm and then into cytoplasm. The higher the activity of the nucleolus and the more core structures in it, the higher is the protein synthesis in the cell and its biosynthetic activity [8]. Therefore, the results of our experiments indicate a significant increase in protein biosynthesis in nephrocytes. On the one hand, it is in good agreement with modern ideas about the mechanisms of cellular action of short-chain peptides and amino acids. It is believed that these substances can influence the genetic regulation of nucleic acid synthesis and, as a consequence, ribosomal protein synthesis [8]. At the same time, the established effect can clarify the mechanisms of anti-lithogenic action of peptide extract of pig kidney tissue. Thus, the general strengthening of cellular protein synthesis can be accompanied by an increase in the number and activity of intrarenal crystallization inhibitors: osteopontin, Tamm-Horsfall protein, and bikunin, properties of which are well described in modern literature [3]. In addition, in recent years, increasing attention has been paid to the study of the organic matrix of kidney stone. Experiments show that the matrix can contain tens and even hundreds of endogenous proteins, including stimulants and crystallization inhibitors [10]. Today, there is an opinion that the modification of the structure and function of stone matrix can interfere with lithogenesis. Comparing the previously revealed litholytic effect of the peptide complex of pig kidney tissue and the results of the present study, we can assume that an increase in protein biosynthesis in nephrocytes has significant importance for the emergence of the anti-lithogenic effect of the peptide complex of pig kidney tissue.

\section{Conclusions}

1. Three-week application of the peptide complex of pig kidney tissue in experimental oxalate nephrolithiasis is accompanied by an 
increase in the morphofunctional activity of nucleolar organizers of nephrocytes compared to the disease control.

2. An increase in activity of nucleolar cell apparatus appeared both in their increase of number of nucleoli and number of silver granules (core structures) and the increase of cell count with a large number of core structures for 1 nucleus.

Conflict of interest. The authors declare that there is no conflict of interest.

\section{References:}

1. Zharikov A.Yu., Kiselev V.I., Saldan I.P., Zharikova G.V., Lepilov A.V., Bobrov I.P. Morphological assessment of the impact of peptide complex pf pig kidney tissue on the course of experimental kidney stone disease. Bulletin of Experimental Biology and Medicine. 2017; 164(8): 237240.

2. ZharikovaG.V.,ZharikovA.Yu.,Kiselev V.I., Mazko O.N., Makarova O.G., Kiryakova V.O. The influenceof thepeptidecomplex of pigkidneyson the free radical oxidation by experimental urolithiasis. The Siberian Scientific Medical Journal. 2017; 37(2): 17-21.

3. Zverev Ya.F., Zharikov A.Yu., Brukhanov V.M., Lampatov V.V. Modulators of oxalate nephrolithiasis. Inhibitors' crystallization. Nephrology. 2010; 14(1): 29-49.

4. Zharikov A.Yu., Brukhanov V.M., Zverev Ya.F., Lampatov V.V. Current methods of modeling of oxalate nephrolythiasis. Nephrology. 2008; 12(4): 28-35.

5. Daskal Y., Komaromy L., Busch H. Isolation and partial characterization of perichromatin granules. A unique class of nuclear rnp particles. Experimental Cell Research. 1980; 126(1): 39-46.

6. Bobrov I.P., Avdalyan A.M., Klimachev V.V., Lazarev A.F., Gervald V.Ya., Dolgatov A.Yu., Samuilenkova O.V., Kovrigin M.V., Kobyakov D.S. Modification of histochemical method of identification of nucleolar organizers at histological sections. Archive of Pathology. 2010; 72(3): 35-37.

7. Bobrov I.P., Avdalyan A.M., Cherdantseva T.M., Klimachev V.V., Lazarev A.F., Brukhanov V.M., Doroshenko V.S., Gervald V.Ya., Dolgatov A.Yu., Kovrigin M.V. Modified method of identification of argyrophilic proteins of the nucleolar organizer area at paraffin sections. Morphology. 2010; 138(5): 65-67.

8. Chelidze P.V. Fibrillar centres in the nucleoli of cultured pek cells after the action of actinomycin D. Cytology. 1982; 24(2): 137-143.

9. Khavinson V.Kh., Soloviev A.Yu., Tarnovskaya S.I., Lin'kova N.S. The mechanism of biological activity of short peptides: penetration into a cell and epigenetic regulation of gene expression. Successes of Modern Biology. 2013; 133(3): 310-316.
10. Kaneko K.,Nishii S., Izumi Y,, Yasuda M.,Yamanobe T., Fukuuchi T., Yamaoka N., Horie S. Proteomic Analysis after Sequential Extraction of Matrix Proteins in Urinary Stones Composed of Calcium Oxalate Monohydrate and Calcium Oxalate Dihydrate. Analytical Sciences. 2015; 31(9): 935-942.

\section{Contacts}

Corresponding author: Zharikova Ganna Viktorovna, lecturer of the Department of General and Biological Chemistry, Clinical Laboratory Diagnosis, Altai State Medical University, Barnaul. 656038, Barnaul, Lenina Prospekt, 40.

Tel.: (3852) 566938.

E-mail: ganna1704@mail.ru

\section{Author information}

Bobrov Igor Petrovich, senior staff scientist of the Morphological Laboratory of the Center of Medical and Biological Research, Altai State Medical University, Barnaul.

656038, Barnaul, Lenina Prospekt, 40.

Tel.: (3852) 669927.

E-mail: science@agmu.ru

Mazko Olesya Nikolayevna, Candidate of Biological Sciences, Senior Scientific Researcher of the Biomedical Laboratory of the Center of Medical and Biological research, Altai State Medical University Barnaul.

656038, Barnaul, Lenina Prospekt, 40.

Tel.: (3852) 669927.

E-mail: olesia.mazko@yandex.ru

Makarova Olesya Gennadyevna, Candidate of Pharmaceutical Sciences, Senior Scientific Researcher of the Biomedical Laboratory of the Center of Medical and Biological Research, Altai State Medical University, Barnaul.

656038, Barnaul, Lenina Prospekt, 40.

Tel.: (3852) 669927.

E-mail: olesia552@mail.ru

Lepilov Aleksandr Vasilyevich, Doctor of Medical Sciences, Head of the the Department of Forensic Medicine and Pathological Anatomy named after professor V.N. Kryukov with the Course of FVE, Altai State Medical University, Barnaul. 656038, Barnaul, Lenina Prospekt, 40.

Tel.: (3852) 408439.

E-mail: science@agmu.ru

Zharikov Aleksandr Yuryevich, Doctor of Biological Sciences, Associate Professor, Head of the Department of Pharmacology, Altai State Medical University, Barnaul.

656056, Barnaul, ul. Papanintsev, 126.

Tel.: (3852) 241859.

E-mail: zharikov@agmu.ru 